\title{
Principais Desafios na Saúde
}

\section{Key Challenges in Health}

José Carlos Lopes Martins ${ }^{1}$

\section{RESUMO}

Os sistemas de saúde estão submetidos a grande pressão por fatores externos e internos, os quais exigem um processo de adaptação constante no modelo governance, na organização do sistema e no financiamento para que a sua sustentabilidade e a equidade possam ser asseguradas; a adaptação às novas realidades não pode ser só normativa, tem de ser fundamentalmente organizacional, económica e pragmática.

Neste artigo são identificadas no sistema de saúde português mudanças que urge levar a cabo; desde logo uma separação clara e transparente dos diferentes papéis que o Estado vem desempenhando com manifesta ineficiência, devendo o Ministério da Saúde centrar a sua atuação primordialmente na regulação forte e efetiva e na contratualização competente, quer junto do setor público quer junto do setor privado, de serviços que lhe compete assegurar mas não necessariamente prestar. Ao mesmo tempo é também urgente a racionalização da oferta com diversificação de formas de gestão de unidades públicas, nomeadamente com parcerias público-privadas que constituem um potente fator de benchmarking para toda a rede e sobre as quais há evidência de aportarem value for money para o Estado.

Não se conhece com rigor a magnitude da ineficiência no nosso sistema de saúde, mas sabe-se que há enormes ganhos a capturar quer a nível da governance do sistema, quer da arquitetura da oferta, quer da melhoria de performance das unidades prestadoras.

PALAVRAS-CHAVE: Financiamento de Cuidados de Saúde; Portugal; Prestação de Cuidados de Saúde; Setor Privado; Setor Público 


\section{ABSTRACT:}

The health systems are under great pressure from internal and external factors that demand constant changes to the governance model, the organisation of the system and funding to ensure its sustainability and equity; the adaptation to new situations cannot only be legislative, it basically has to be organisational, economic and pragmatic.

This article identifies changes in the Portuguese health system that have to be implemented urgently; first of all the clear and transparent separation of the different roles that the state plays with obvious inefficiency. The Health Ministry should focus its actions on strong, effective regulation and competent contracting of the services that it has to ensure, but not necessarily provide, from the public and private sectors. Likewise, the rationalisation of the offer, with diversification of the means of management of the public units is also urgent, namely with public-private partnerships that are a powerful benchmarking factor for the entire network and regarding which have been proven to provide value for money for the state.

The true inefficiency of our health service is unknown, but we do know there are gains to be made both in terms of system governance and in the architecture of the system and the improved performance of the provider units.

KEYWORDS: Delivery of Health Care; Healthcare Financing; Portugal; Private Sector; Public Sector

A saúde tem um importante papel no desenvolvimento social e económico e enfrenta hoje, com intensidade redobrada, desafios que exigem respostas coerentes e rápidas.

As pressões para obter maior eficiência e controle de despesa têm que ser balanceadas com o imperativo moral de manter o acesso universal aos cuidados necessários, uma equação complexa que requer visão clara, estratégias adequadas e ações firmes e despreconceituosas.

O setor da saúde é parte integrante da economia nacional e, nessa medida, submetido a imperativos económicos e financeiros que podem vir a afetar de forma significativa a afetação de recursos e/ou a acessibilidade equitativa aos cuidados, se não formos capazes de perceber as alterações sociais, culturais e económicas que estão a ocorrer e os riscos associados a essas alterações (sobretudo em períodos de fraco ou nulo crescimento económico), mas também se não percebermos e aproveitarmos as oportunidades de mudança que surgem, sobretudo num sistema como o nosso que tem permanecido estático, com um modelo de governação desadequado e uma ineficiente utilização dos recursos.

Há uma multiplicidade de fatores internos e externos que influem na saúde, e da sua interação resultarão mudanças mais ou menos acentuadas que exigirão um processo de adaptação constante, adequando a forma de governação do sistema, a organização e o financiamento de modo a garantir sustentadamente com equidade o acesso dos cidadãos à saúde. Uma mudança efetiva do sistema, adaptando-o às novas realidades, tem de ser normativa, organizacional e económica.
Desde logo é imperioso que se proceda a uma separação clara e transparente dos diferentes papéis que o Estado - o Ministério da Saúde -, continua a desempenhar em simultâneo. É um óbvio fator de ineficiência e opacidade o facto de o Estado ser ao mesmo tempo financiador/comprador, prestador/vendedor e regulador; acresce ainda que os Governantes da saúde, independentemente das pessoas em concreto que em cada momento ocupam os cargos, comportam-se mais como gestores operacionais do Serviço Nacional de Saúde, do que como órgãos de condução de política nacional e de definição de estratégias abrangentes que envolvam outros stakeholders do sistema de saúde e não só do Serviço Nacional de Saúde.

Esta sobreposição de papéis, nomeadamente de financiador e de prestador baseia-se na ideia de que a equidade só é alcançável se o Estado for o prestador direto. Ideia errada na medida em que não é a detenção e a gestão direta da produção de cuidados que garante o acesso e a equidade, mas sim o financiamento e o sistema fiscal e a regulação.

Seguindo as boas práticas da governação, estou certo de que o Estado virá a centrar mais o seu papel numa regulação forte e efetiva e a desenvolver também cada vez mais competências de contratualizador.

É precisamente como contratualizador que, o Ministério da Saúde, mais precisamente a estrutura de Administração do Sistema (ACSS), deverá entrar em linha de conta quer com o setor público quer com o setor privado.

De facto, a estrutura da oferta de cuidados em Portugal sofreu nos últimos anos uma grande alteração em dois eixos essenciais: i) diversidade de formas de gestão de hospitais públicos com o aparecimento de parcerias pú- 
blico-privadas e ii) crescimento qualitativo e quantitativo do setor privado.

Estas duas realidades muito fortes, dinâmicas e com enorme potencial de contribuir para a melhoria de eficiência e de qualidade da globalidade do sistema de saúde, não têm sido devidamente aproveitadas pelos decisores políticos.

Por um lado, o programa das parcerias não só ficou bastante aquém do número que havia sido programado, como existe em relação às que estão a operar um sentimento difuso de alguma animosidade por desconhecimento e preconceito; de facto há, não só, evidência do "value for money" para o Estado desta solução, como também as PPPs são, através do processo de benchmarking, uma potente alavanca de melhoria de performance no conjunto da rede. As posições preconceituosas e fechadas às evidências práticas, não podem contaminar decisões que devem ser tomadas tendo só em conta o que é melhor para os doentes, para os contribuintes e para a sociedade.

Por outro lado o setor privado, que representa hoje cerca de $15 \%$ das consultas hospitalares, 15\% das cirurgias e 13\% de doentes saídos (por referência ao total do SNS), sofreu nos últimos anos um enorme avanço tecnológico, uma acentuada modernização e profundas alterações na organização, como por exemplo a crescente opção por parte de médicos qualificados de trabalho exclusivo em Unidades Privadas, a constituição de equipas estruturadas, a pluridisciplinaridade e totivalência, o desenvolvimento de competências de ensino e investigação, a acreditação e certificação externa, o forte desenvolvimento do management, etc. De tal forma que grande número de Unidades Privadas estão em plenas condições de integrar o perímetro da oferta com quem o Estado pode contratualizar competitivamente serviços, com quem pode estabelecer processos institucionaliza- dos de cooperação e junto de quem pode promover a integração de Hospitais Privados nas redes de referenciação, desde que cumpram os requisitos para esse efeito.

Mesmo desconhecendo a magnitude da ineficiência, sabemos que há enormes ganhos de eficiência a capturar quer a nível macro, quer na contínua melhoria de performance das unidades prestadores, em grande parte induzida pelas alterações de formas de governação e de arquitetura do sistema referidas atrás.

A eficiência na alocação de recursos é, sem dúvida, pressuposto essencial de sustentabilidade do sistema.

A trajetória dos custos em saúde vai continuar a subir, principalmente impulsionada pela inovação terapêutica e por outros fatores demográficos e sociais e, para the fazer face, não pode ser lançada mão ao recurso ao crescimento da receita via aumento de imposto porque é já uma solução esgotada e fortemente penalizadora para cidadãos, famílias e empresas.

Os últimos trinta anos foram dedicados a consolidar os princípios de generalidade, de cobertura universal, de gratuidade no momento do consumo e a procurar "aguentar" a pressão dos custos com medidas conjunturais de curto prazo. Contudo, os desafios que se colocam atualmente e no futuro próximo ao sistema de saúde não podem, do meu ponto de vista, ser resolvidos sem opções claras, racionais, estruturadas e despreconceituosas, que salvaguardando princípios fundamentais de acessibilidade, equidade e solidariedade garantam a sustentabilidade do sistema com estes atributos.

CONFLITOS DE INTERESSE: O autor declara a inexistência de conflitos de interesse na realização do trabatho.

FONTES DE FINANCIAMENTO: Não existiram fontes externas de financiamento para a realização deste artigo. 